Open Access

\title{
Examining the influence of native and non- native English-speaking teachers on Korean EFL writing
}

\author{
Andrew Schenck(i)
}

\author{
Correspondence: Schenck@hotmail. \\ com \\ The State University of New York, \\ Korea, 119 Songdo Moonhwa-Ro, \\ Incheon 21985, Korea
}

\begin{abstract}
Both Native English-Speaking Teachers (NESTs) and Non-Native English-Speaking Teachers (NNESTs) may have advantages as writing instructors, yet little is known about how they actually influence writing in EFL contexts like South Korea. To address this issue, 76 high proficiency Korean EFL university students from the International Corpus Network of Asian Learners of English (ICNALE) were separated into a group that received extensive native English speaker instruction $(n=57)$ and a group that did not $(n=19)$ using a self-survey. Analysis of essay content revealed that words used by Korean EFL writers with more NEST instruction are similar in difficulty and variety to native English writers. Concerning style, Korean EFL learners with more NEST instruction used stances to evaluate, validate, and state personal opinions, while learners with less NEST instruction used speech formulas and more unbiased logical arguments. Regarding grammar, Korean EFL learners with extensive NEST instruction used more sophisticated vocabulary, word forms, and verb tenses to create a novel argument using personal experience, whereas Korean EFL learners with low NEST instruction tended to use formulaic and logical arguments with more accuracy. Overall, results suggest that NEST instruction in Korea promotes more creativity and sophistication in composition, while NNEST instruction encourages more accurate use of language. In accordance with the findings, curricula or teacher training may be developed to ensure that each type of instruction shares the strengths of its counterpart.
\end{abstract}

Keywords: EFL, Korean, ICNALE, Writing, Content, Stances, Hedges, Grammar, NEST

\section{Introduction}

Recently, legislators in South Korea rescinded a law banning English education in the first and second grades of elementary school. This law, which had been designed to keep children that are "too young to learn a foreign language" from being negatively impacted (Jung, 2019, p. 2), has been highly criticized by both parents and teachers who argue that it will only deepen the growing hardship of poor families, who cannot afford English instruction through extracurricular private academies (Jung, 2019). This issue is nothing new. It is the latest in a series of controversial debates over the best means to promote English education in Korea.

Ultimately, increased English classes both inside and outside the public-school classroom reveal an intense desire to overcome perceived problems with traditional

(c) The Author(s). 2020 Open Access This article is distributed under the terms of the Creative Commons Attribution 4.0 International License (http://creativecommons.org/licenses/by/4.0/), which permits unrestricted use, distribution, and reproduction in any medium, provided you give appropriate credit to the original author(s) and the source, provide a link to the Creative Commons license, and indicate if changes were made. 
language instruction in South Korea, which often promotes rote memorization and teacher-centric instruction (DeWaelsche, 2015). This type of learning, which helps students achieve in more receptive tasks like reading and listening (Kwon, Yoshida, Watanabe, Negishi, \& Naganuma, 2004; Programme for International Student Assessment, 2015), may inhibit performance on communicative tasks like writing. This view is supported by evidence of TOEFL performance in 2009. During this period, average writing scores were well below the global average (Kang, 2009). Despite more than 6 years of English instruction in public school classes, learners still had problems with writing tasks, adaption of language to real situations, and critical thinking skills needed to make a written or spoken argument (Kim \& Kim, 2005; Niederhauser, 2012).

To counter perceived problems with educational techniques which failed to cultivate writing skills, several curricular changes were enacted. In addition to communicative activities, writing assessments such as the National English Ability Test (NEAT) were introduced at the elementary school level (Moodie \& Nam, 2016). While a positive step forward, such reforms resulted in failure, partly due to teachers who were unskilled or unequipped to implement such changes (Byun et al., 2011). Research suggests that many Korean instructors currently lecturing through English Medium Instruction (EMI) still need additional language training so they may teach writing more effectively (Kim, 2014).

Widespread dissatisfaction with attempted reforms for Korean teachers and learners of English has prompted both parents and educators to seek out the use of native English speakers who can teach the requisite communicative skills. To accommodate parental demand, widespread expansion of extracurricular academies which employ native English speakers has resulted (Kim \& Lee, 2010). In addition to extracurricular activities, government programs like the English Program in Korea (EPIK) have been developed to hire native-speaking English teachers for public schools. The introduction of Native English-Speaking Teachers (NESTs), designed to enhance writing skills through natural communication, is conventionally thought to have a positive effect on production and critical thinking skills. Research does suggest that NESTs can have a positive effect on the completion of task-based activities (Jiang \& Li, 2018). At the same time, these NESTs may lack a valid teaching credential or experience in English education, making them illequipped to teach. Lacking teaching experience, NESTs may not have an explicit awareness of underlying language systems, precluding effective instruction (Keh, 2017). NESTs, like their NNEST counterparts, may not have the repertoire of skills needed to prepare students to write effectively.

Potential problems of both NEST and NNEST instructors has sparked a controversial debate over the efficacy of each. While supporters of NNESTs contend that they provide effective language development through understanding of the Korean culture and language, as well as a shared understanding of the L1 (Brewer, 2016; Chun, 2014), they may overemphasize literal use of grammar and vocabulary, without an adequate understanding of the social and connotative world knowledge needed to use them. NESTs may have more knowledge about contextual and social concepts needed to use grammar and vocabulary, yet they may also lack educational experience or an understanding of the host culture, which may inhibit communication of key concepts (Wang \& Lin, 2013). While debate continues as to the efficacy of NESTs and NNESTs, little research 
has been conducted to analyze how these teachers impact communicative competence in an EFL context like South Korea.

\section{Potential impact of NESTs vs. NNESTs on writing}

NNEST teachers may have an advantage in teaching grammatical features or literal denotation of vocabulary through comparison and contrast with a Korean learner's L1, whereas NESTs may understand social contexts, connotation, and pragmatic usage of vocabulary within the target language, leading to more advanced use of language in authentic contexts. While this distinction has been proposed (Brewer, 2016; Chun, 2014; Wang \& Lin, 2013), very little is known about the effects of such instruction. Cultural and linguistic influences of both NESTs and NNESTs may affect aspects of writing such as content, style, and grammar, warranting further investigation.

Content may be influenced by interaction with both NEST and NNEST instructors. Although impartial evaluation of content is a difficult task, research suggests that discrete measures of lexical variety (diversity of words), sophistication (word difficulty), and density (the number of content words, as opposed to grammar) are objective measures of quality writing, closely correlating to scores assigned by human raters (Lu, 2012; Read, 2000; Yu, 2009). Because such measures provide a more empirical, unbiased foundation for the judgement of differences in writing, they represent an ideal tool to judge the impact of NEST and NNEST instructors. A teacher's ability to help learners with lexical variety, sophistication, and density may differ for both NEST and NNEST instructors. NESTs often possess a more complex lexicon with increased word variety, sophistication, and density, which can be advantageous in the classroom. Despite such an advantage, it is a mistake to think that this implicit knowledge will automatically be imparted through natural productive tasks. Research suggests that mere exposure to authentic communicative tasks is not enough to learn a language (Harper \& de Jong, 2004). When learning metaphors, for example, which are imbued with culturally figurative language, EFL learners tend to benefit more from systematic and explicit explanations (Veliz, 2017). To be sure, an explicit understanding of underlying language systems, referred to as Teacher Language Awareness (TLA) (Andrews \& Svalberg, 2017), is required for effective teaching. Teachers who lack such knowledge may avoid focusing on aspects of content that are problematic for learners (Keh, 2017). Because NESTs with little or no teaching experience may not have extensive TLA, they may rely too heavily on implicit techniques for language learning, inhibiting learner development. While NNESTs may lack some sophisticated knowledge of register and cultural context, they may provide more systematic and explicit instruction needed to learn a language. As second language learners themselves, NNESTs may be better able to explicitly explain a feature in English.

In addition to content (lexical variety, sophistication, or density), NNEST and NEST instruction may have a different impact on discourse within writing. Merriam Webster defines discourse as "a mode of organizing knowledge, ideas, or experience that is rooted in language and its concrete contexts (such as history or institutions)" (Discourse, 2020). As this definition implies, discourse is closely related to the cultural institutions and contexts in which the language was created (Murphy, 2010). This is why we do not picture Cinderella wearing Nike flip-flops, even though this information 
may not be explicitly provided. Indeed, each speech community or cultural context uses a precise set of language to establish its own identity (Ortaçtepe, 2013). It is this language set that L2 English learners may use to build a type of hybrid style that is "largely, but not completely, native-like" (Pérez-Llantada, 2014, p. 84). Korean EFL learners, for example, may "borrow" Western style stances and hedges to emulate native counterparts, leading to higher values for writing quality (Min, Paek, \& Kang, 2019, p. 12). While it is clear that the English speech community may use language that improves perceived writing quality, the extent to which NEST or NNEST instructors teach this culturally specific language is unclear. NEST instructors may use this language to teach rhetorical concepts like stance and hedges, leading to expression of agreement, disagreement, or opinion. If these teachers are not explicitly aware of such concepts, however, systematic and meaningful learning opportunities may not be provided. NESTs' more advanced knowledge of specific language may also be ineffective as a teaching tool when EFL learners lack basic communication skills (Harper \& de Jong, 2004). While NESTs may have a heightened awareness of culturally laden terms and linguistic devices, NNESTs may provide a better bridge between basic aspects of discourse in both languages, leading to a better foundational understanding of writing.

Finally, NNEST and NEST instruction may have a different impact on grammar within writing. In addition to words that denote aspects of content such as verbs, nouns, adjectives, and adverbs, there are bound and free morphological features that serve a grammatical function (White, 2009). Bound morphological features, present on content words like verbs and nouns, reveal aspects of tense (walked), agreement (walks), or number (sneakers). In addition to bound morphological features, free morphemes like pronouns, auxiliary verbs, determiners, and conjunctions may be used to clarify and expand meaning within writing content (Master, 1996). Concerning both free and bound grammatical features, NESTs may have an advantage in creating quality contextual circumstances for their use. They may, for example, provide accurate input and communicative contexts for correct use of determiners like $a$, $a n$, or the. Unlike non-native speakers, NESTs may provide more accurately conjugated nouns and verbs within input, thereby facilitating acquisition. Finally, they may provide more fluent and longer discourse through the use of conjunctions like and or addition. NESTs may also be at an advantage to identify errors in use of grammatical features that are not present in the Korean L1, such as the English determiner, present perfect tense, and phrasal verb. As with aspects of content and style, understanding and correct use of grammar by the teacher may not guarantee acquisition. Explicit grammatical emphasis may be needed to help foreign language learners focus on a target feature (DeKeyser, 2015; Dyson, 2018; Dyson \& Håkansson, 2017; Pienemann, 1989). NNEST instructors have a distinct advantage in providing links to the L1 which may promote acquisition. Through providing cross-linguistic comparison and contrast, Korean EFL learners may be better able to understand and acquire grammatical features.

Both NEST and NNEST instructors may have strengths that help their EFL learners produce better content, discourse, and grammar in writing. Despite potential strengths, little research has been conducted to investigate how such advantages may actually influence English learners. Lacking a clear understanding of how both NEST and NNESTs can best be utilized, both teacher groups receive skepticism. They have 
become subject to bias and discrimination, which may negatively impact instruction, as well as cooperative educational efforts between the two groups.

\section{Problems faced by NESTs and NNESTs}

Insufficient evidence concerning the positive impact of NESTs and NNESTs on EFL learner development has fueled biases that depict both groups as inferior. NNESTs in EFL countries like South Korea, for example, are often thought to be less effective due to a lack of native proficiency. This bias, referred to as native speakerism, may cause teachers to lose confidence or suffer from an inferiority complex. Programs like the English Program in Korea (EPIK) also perpetuate this bias through recruiting teachers only from "inner circle" countries like the United States, England, Australia and New Zealand (Copland, Davis, Garton, \& Mann, 2016). Not only is the problem of native speakerism present in South Korea, it is found in other countries like Thailand, where professional status of Filipino NNESTs is eroded by the misconception that native English skill is necessary for teaching (Ulla, 2019). Like non-native counterparts, NESTs often suffer from prejudice and discrimination, which is fueled by the view that inexperience or lack of teacher training makes them ineffective (Copland et al., 2016).

Evidence suggests that biases against both NEST and NNESTs in EFL contexts hamper the implementation of English programs like EPIK, primarily through a lack of collaboration, cultural conflicts, or an unwillingness to work together among the two groups of teachers (Copland et al., 2016). While such problems may have cultural or even political foundations, they are ultimately fueled by a lack of knowledge about how each type of instruction can be effectively utilized. Past studies have focused primarily on attitudes and perceptions of the teacher groups (Ma, 2012), which has limited understanding of the actual impact on EFL learner speech or writing. Through further research, strengths of both groups may be identified, leading to more effective utilization of teachers, a reduction of negative biases, and establishment of more effective cooperative efforts among both groups.

\section{Research questions}

Due to the need for further investigation of the impact of NESTs and NNESTs, this study was conducted to examine differences in academic writing among Korean EFL learners who are exposed to native English instructors and those who are not. Such study may lead to more effective use of both NESTs and NNESTs, particularly in cooperative efforts like EPIK. In accordance with a need for further research, the following questions were posed:

1. Does word choice of Korean EFL writers exposed to more native speaker instruction significantly differ from that of Korean EFL writers with little or no exposure to native speaker instruction? How does word choice of each Korean group compare to that of native English writers?

2. Does word choice in writing between groups reveal differences in content such as lexical variety, lexical sophistication, and lexical density?

3. Does word choice in writing between groups reveal differences in the utilization of stylistic devices like stances and hedges? 
4. Does word choice in writing between groups reveal differences in the utilization of grammatical features?

\section{Method}

To examine essays produced by Korean EFL learners, the International Corpus Network of Asian Learners of English (ICNALE) was used. This 2-million-word corpus contains essays from college students (including graduate school) from ten different EFL countries. Included in the corpus are essays from Korean EFL learners and native English speakers, which could be used for comparison (Ishikawa, 2018). The corpus also has an Infosheet (self-survey) completed by each learner, which includes demographic information like age and major, along with background details such as the amount of instruction received from NESTs (Question 31).

\section{Research design}

The aim of this study was to see how word choice differs between learners who receive a large amount of NEST instruction, learners who receive little NEST instruction, and native English students. To fulfill this aim, a mixed-methods approach was used. Word frequencies from the writings of the three groups (taken from ICNALE) were quantitatively tested for significant differences using a paired-samples t-test. Following this statistical examination, aspects of content, style, and grammar where quantitatively examined using statistics of word frequency or variety related to each respective aspect of writing (content, style, and grammar). This investigation was then followed by qualitative examination of learner essays.

\section{Essays collected from the ICNALE Corpus}

Essays in the ICNALE corpus were strictly controlled to ensure that all participants wrote about the same topics. They were given the same two prompts (Ishikawa, 2013, p. 97):

Topic A: It is important for college students to have a part-time job.

Topic B: Smoking should be completely banned at all the restaurants in the country.

Following receiving prompts, all participants were given from 20 to $40 \mathrm{~min}$ to write an essay from 200 to 300 words. No dictionaries or other reference tools were allowed (Ishikawa, 2013). Control of topics in this way helped to increase the validity of contrastive analysis between groups in the present study.

\section{Participants from the ICNALE Corpus}

For this study, essays from 76 Korean EFL university learners at the highest proficiency level, B2+, were selected from the ICNALE corpus. The essays had been assigned the $\mathrm{B} 2+$ level because they were at Vantage or higher stages of the Common European Framework of Reference (CEFR) according to proficiency values from tests like the TOEIC, TOEFL, and IELTS (Ishikawa, 2018). Each learner wrote two essays about the same topics, having a part-time job and banning smoking, meaning that 76 learners had a total of 152 essays. Using essays from the highest proficiency learners in the ICNALE corpus ensured that all writers had an equivalent degree of competence in writing. All essays came from Korean EFL university learners who ranged in age from 
19 to 29 and majored in a variety of subjects from the sciences, social sciences, and humanities. For comparison, essays from 100 native English speakers (a total of 200 essays) were also selected from the ICNALE corpus. These essays also came from university learners who ranged in age from 19 to 29 and majored in a variety of subjects from the sciences, social sciences, and humanities.

From the 152 Korean EFL learner essays from the B2+ level, 38 essays came from 19 learners who reported in the ICNALE self-survey that they had little or no instruction with native speakers (numbers 1 to 3 on a Likert scale), and 114 essays came from 57 Korean EFL learners who reported more extensive instruction with native English speakers (numbers 4 to 6 on a Likert scale). While the self-survey does not provide a precise description of how much experience learners have had with native speaking instructors, the separation of survey scores helps to ensure that one participant group has more NEST instruction than the other.

\section{Preparation of Corpus data and analysis}

Essays in ICNALE were separated by learner group and compiled into sub-corpora (text files) for analysis. The corpus of 38 essays from Korean EFL learners with low NEST support had 9312 words, while the corpus of 114 essays from Korean EFL learners with high NEST support had 26,753 words. Finally, the corpus of 200 native English writer essays had 44,966 words. To answer the research questions, word frequency values were obtained from each corpus using the online program called lextutor.ca.

To answer research question one, which sought to examine preferences in word choice, words that were used at least 10 times in one or more of the corpora (Low NEST Support, High NEST Support, and Native English Writer) were recorded in a spreadsheet for analysis. Next, frequency counts for words from the High NEST Support and Native English Writer corpora were adjusted to match the size of the smaller Low NEST Support corpus using the following calculation:

\section{Frequency of Word in Corpus B * (Size of Corpus A / Size of Corpus B)}

Following this calculation, which was conducted to proportionally adjust word frequencies for the High NEST Support and Native English Writer corpora to those of the Low NEST Support corpus, word frequencies of each corpus were statistically compared using a paired samples t-test to reveal significant (or insignificant) differences.

Research question two aimed to investigate differences in content. In accordance with this aim, lexical density, word difficulty, word types, and tokens (total number of words) were calculated for each group of essays (Low NEST Support, High NEST Support, and Native English Writer) using lextutor.ca. Amount of content was evaluated using lexical density. A high value for lexical density, which reflects a larger number of content words like nouns or verbs (as opposed to grammatical or functional features), may suggest that meaning within writing is more complex or substantial. Difficulty of content was evaluated by examining the number of vocabulary words present from the New Academic Word List (NAWL). When added to a list of core words called the New General Service List (Stoeckel \& Bennett, 2015), the NAWL's 570 word families 
account for approximately $92 \%$ of the total words (tokens) in academic texts (Browne, Culligan, \& Phillips, 2013). Because the NAWL accounts for $10 \%$ of all words in academic texts, yet only comprises $1.4 \%$ of the words in fiction collections, the NAWL represents an ideal measure of difficulty in academic essays (Coxhead, 2000). The presence of more academic words may suggest additional sophistication of essay content. Finally, variety of content was examined by looking at type / token ratios. Whereas a type represents one root word, or lemma (e.g., eat), the token represents the instantiation of each type (e.g., eating, eaten, ate, etc.). A larger ratio (a larger variety of tokens) is thought to signify more sophisticated content (Laufer \& Nation, 1995).

To answer research question three, which sought to evaluate how discourse (style) may differ, categories for hedges and stances employed in the study by Min et al. (2019) were utilized. These hedges and stances reveal a writer's ability to increase and decrease the significance of opinions. They were divided into the following categories (Table 1):

Prototypical stances and hedges from each category were tallied from each corpus of essays (Low NEST Support, High NEST Support, and Native English Writer). Resulting values were then adjusted for corpus size as in the procedure for research question one. Next, use of the words was qualitatively analyzed. While not an exhaustive list of discourse words, comparison in this way yielded insights about how commonly used stances and hedges were employed by each group examined within this study.

To answer research question four, which was designed to evaluate grammar, words from specific categories for auxiliary verbs, pronouns, determiners and conjunctions were selected from Systems in English Grammar by Master (1996). For auxiliary verbs, both $d o$ and can were selected for analysis. In addition to use of the base form, evaluation of forms like does, did, done, and could were evaluated to reveal an awareness of tense and agreement. Subject pronouns $I$, you, they and we were also selected for analysis. Differences in pronouns may reveal an attempt to influence the reader through explaining personal experiences (e.g., I used to smoke.), addressing the reader (e.g., You may think that secondhand smoke is harmless, but...), or creating a more general example (e.g., They will suffer from secondhand smoke.). Next, the definite and indefinite

Table 1 Types of stances and hedges evaluated in the study

\begin{tabular}{|c|c|}
\hline Type of stance or hedge & Examples \\
\hline 1. epistemic certainty & $\begin{array}{l}\text { apparent, certain, obvious, actually, certainly, definitely, conclude, notice, } \\
\text { prove }\end{array}$ \\
\hline 2. epistemic likelihood & likely, possible, probable, apparently, perhaps, probably, assume, guess, seem \\
\hline 3. attitude & $\begin{array}{l}\text { annoyed, disappointed, nervous, amazingly, essentially, fortunately, agree, } \\
\text { expect, feel }\end{array}$ \\
\hline 4. evaluation adjectives & appropriate, bad, important \\
\hline $\begin{array}{l}\text { 5. ability or willingness } \\
\text { adjectives }\end{array}$ & able, anxious, careful \\
\hline 6. ease or difficulty adjectives & difficult, easy, hard \\
\hline 7. style adverbs & according to, generally, usually \\
\hline 8. desire and attention verbs & decide, hope, want \\
\hline 9. causation and effort verbs & enable, manage, require \\
\hline 10. communication verbs & claim, insist, say \\
\hline 11. hedges & in general, kind of, typical \\
\hline
\end{tabular}


articles ( $a, a n$, and the ) were chosen to examine how determiners were utilized. Heightened use of articles may represent a more sophisticated or systematic use of the feature. Finally, types of conjunctions (and, addition) were selected for evaluation, along with words for relative and conditional clauses (if, who, which, where, how, whether). Through examining these words, aspects of sentence length and complexity could be evident. Following selection, words from each grammar category were tallied from all three corpora of essays (Low NEST Support, High NEST Support, and Native English Writer). Resulting values were then adjusted for corpus size as in the procedure for research question one. Next, grammatical word use was qualitatively analyzed in individual learner essays. Through such analysis, grammar related to auxiliary verbs, tense, agreement, pronouns, determiners, and conjunctions could be evaluated. While the words included in this study do not form an exhaustive list, they represent a foundation from which key grammatical characteristics may be ascertained.

\section{Results and discussion}

\section{Research question one: differences in word preference}

Results of vocabulary analysis suggest that there are indeed significant differences in use of high frequency words. Although essay topics were the same for each writer, vocabulary from Korean EFL learners with more instruction from a native speaker differed significantly from those with little or no instruction from a native speaker $(t=$ $3.11 ; p=.002)$. At the same time, the writing of Korean EFL learners with high NEST support was not significantly different from their native English-speaking counterparts $(t=-.64 ; p=.520)$. This result suggests that EFL learners with high NEST support do indeed develop more native-like writing (See Table 2).

Statistical comparison of frequency of commonly used vocabulary suggests that there is indeed a difference in writing between groups. Follow-up analysis of individual word use suggests that these differences may be related to differences in content, style, and grammar.

\section{Research question two: differences in content}

Analysis of individual words suggests that there are indeed differences in content. While lexical density (number of content words) does not differ considerably (See Table 3), the amount of academic words seems substantially higher in the Korean EFL group with higher NEST support and in the native English speaker group. In the writings of Korean learners with low NEST support, only $4 \%$ of words were

Table 2 Differences in vocabulary use

\begin{tabular}{|c|c|c|c|c|c|c|c|c|}
\hline & \multicolumn{8}{|c|}{ Paired samples test } \\
\hline & \multicolumn{5}{|c|}{ Paired differences } & \multirow[t]{3}{*}{$\mathrm{t}$} & \multirow[t]{3}{*}{ df } & \multirow{3}{*}{$\begin{array}{l}\text { Sig. } \\
(2- \\
\text { tailed) }\end{array}$} \\
\hline & \multirow[t]{2}{*}{ Mean } & \multirow[t]{2}{*}{$\begin{array}{l}\text { Std. } \\
\text { Deviation }\end{array}$} & \multirow[t]{2}{*}{$\begin{array}{l}\text { Std. } \\
\text { Error } \\
\text { Mean }\end{array}$} & \multicolumn{2}{|c|}{$\begin{array}{l}95 \% \text { confidence } \\
\text { interval of the } \\
\text { difference }\end{array}$} & & & \\
\hline & & & & Lower & Upper & & & \\
\hline Pair 1 High NS Support - Low NS Support & 4.86 & 19.45 & 1.56 & 1.78 & 7.95 & 3.11 & 154 & .002 \\
\hline Pair 2 Native Speaker - High NS Support & -.68 & 18.04 & 1.06 & -2.77 & 1.41 & -.64 & 288 & .520 \\
\hline Pair 3 Native Speaker - Low NS Support & 4.01 & 22.89 & 1.86 & .33 & 7.69 & 2.15 & 150 & .033 \\
\hline
\end{tabular}


Table 3 Indicators for content

\begin{tabular}{llll}
\hline & Native & High native support & Low native support \\
\hline Variety: Type Token Ratio & 0.07 & 0.09 & 0.13 \\
Tokens Per Type & 13.47 & 11.06 & 7.63 \\
Sophistication: New Academic Word List (NAWL) & $141(8.0 \%)$ & $86(6.2 \%)$ & $34(4.0 \%)$ \\
Density: Lexical Density & 0.47 & 0.52 & 0.5 \\
\hline
\end{tabular}

contained in the New Academic Word List (NAWL). This value is half that of the native speaker group. In the Korean group with high NEST support, $6.2 \%$ of the vocabulary was academic, which reveals a closer link to the native English speech community. While native speaker group performance is not a benchmark for quality, higher amounts of academic vocabulary may suggest increased sophistication of academic essays.

Qualitative analysis of content appeared to confirm the assertion that content of the Korean group with high NEST support was more academic. Words like anomaly and diminished revealed a sophisticated understanding of vocabulary. Furthermore, more precise descriptions of health issues through words like diabetes, larynx, hygiene, and stroke suggested a more specific and expansive explanation of content.

In addition to more academic words, a larger number of tokens per type in the Korean group with high NEST support (Table 3) suggests that word forms were more diverse and sophisticated than their counterparts with low NEST support. Korean EFL learners with high NEST support had essays with more word variants (e.g., hygiene, hygienic; beneficial, beneficiary; broad, broaden; disturb, disturbed, disturbing, disturbs, etc.). This increased use of different word forms, which included a variety of affixes (e.g., ben or dis) appears to reflect higher complexity of content.

Table 4 Indicators of style: use of stances and hedges

\begin{tabular}{|c|c|c|c|c|}
\hline & & $\begin{array}{l}\text { Low native } \\
\text { support }\end{array}$ & $\begin{array}{l}\text { High native } \\
\text { support }\end{array}$ & Native \\
\hline Evaluation & appropriate, bad, important & 37 & 51 & 39 \\
\hline $\begin{array}{l}\text { Ease or } \\
\text { Difficulty }\end{array}$ & difficult, easy, hard & 4 & 21 & 15 \\
\hline $\begin{array}{l}\text { Causation and } \\
\text { Effort }\end{array}$ & enable, manage, require & 4 & 6 & 5 \\
\hline $\begin{array}{l}\text { Epistemic } \\
\text { Likelihood }\end{array}$ & $\begin{array}{l}\text { likely, possible, probable, apparently, perhaps, probably, } \\
\text { assume, guess, seem }\end{array}$ & 10 & 11 & 20 \\
\hline $\begin{array}{l}\text { Epistemic } \\
\text { Certainty }\end{array}$ & $\begin{array}{l}\text { apparent, certain, obvious, actually, certainly, definitely, } \\
\text { conclude, notice, prove }\end{array}$ & 10 & 7 & 11 \\
\hline $\begin{array}{l}\text { Attitude or } \\
\text { Emotion }\end{array}$ & $\begin{array}{l}\text { annoyed, disappointed, nervous, amazingly, essentially, } \\
\text { fortunately, agree, expect, feel }\end{array}$ & 25 & 24 & 28 \\
\hline $\begin{array}{l}\text { Ability or } \\
\text { Willingness }\end{array}$ & able, anxious, careful & 9 & 4 & 12 \\
\hline Style Adverbs & according to, generally, usually & 15 & 7 & 3 \\
\hline $\begin{array}{l}\text { Desire and } \\
\text { Attention }\end{array}$ & decide, hope, want & 30 & 24 & 30 \\
\hline Communication & claim, insist, say & 12 & 11 & 10 \\
\hline Hedges & in general, kind of, typical & 12 & 10 & 9 \\
\hline
\end{tabular}




\section{Research question three: differences in Discourse and style}

In addition to content, aspects of style appeared to differ between groups. As can be seen from Table 4, Korean EFL learners with higher native speaker instruction utilized more stances for evaluation. These writers used words like appropriate, bad, and important more often as a means to emphasize validity or invalidity of an argument (Table 4). Unlike their counterparts with less NEST instruction, Korean EFL learners with high NEST support used stances with awkward collocations, as in the following examples for the word appropriate:

1. It could be an appropriate solution to help them move out from the addiction.

2. I highly recommend you to find appropriate work, try different jobs and study hard.

In the above examples, the writers are trying to persuade, yet unique word combinations like "move out from the addiction" or "recommend you to find appropriate work" make the arguments appear awkward. In contrast to these awkward statements, Korean EFL learners with low native speaker support used stances with more accurate collocations. Refer to the following examples:

1. That's why many of them are working as interns in order to gain an appropriate experience that would be necessary in their future profession.

2. I think periods of college are not appropriate to do part-time jobs.

Unlike their counterparts, the low native speaker support group of Korean EFL learners used expressions that are more conventional and accurate.

In addition to stances for evaluation, Korean EFL learners with high NEST support utilized stances for ease or difficulty much more often (Table 4). Overall, these stances appear to be used to express personal opinions or preferences about an issue, as a means to persuade the reader. This more overtly partial perspective may reflect an influence of NEST instructors from Western contexts, who may value personal opinion more than group consensus, a hallmark of Confucian societies like South Korea.

In contrast to Korean EFL learners with high support from NESTS, Korean EFL learners with low native speaker support did not use as many stances to evaluate an argument using personal opinion. These learners appeared to rely more on formulaic patterns obtained from input and instruction, thereby revealing a lesser tendency to create novel expressions or express personal opinions. This assertion is supported by low NEST support learners' heightened use of elements of style (according, generally, usually), which may be memorized and may not directly express the personal opinion of a writer. These stances are often used to express opinions indirectly through outside sources (e.g., According to research...). Overall, learners with low NEST instruction appear to use these "unbiased" speech formulas to express an opinion. This perspective is illustrated by more extensive usage of stances for ability or willingness. The word able, for example, is often used with formulaic expressions for reasoning or inference. Refer to the following examples from Korean EFL learners with low NEST support: 
1. If smoking is banned at all restaurants in Korea, we will be able to enjoy the dish more at the restaurants.

2. Since college students are already adults, they should be able to make money for living, independently from their parents.

3. When students have a part-time job and work it, they are able to think about concept of money and consumption.

In the above examples, an argument without personal judgment from the author is expressed. The logical arguments appear to show unbiased opinions of the author, with little awareness of the reader.

Unlike words for evaluation or discussion of ease and difficulty, which are characteristic of Korean EFL learners with high NEST instruction, elements of style or ability are not imbued with clear opinion about the argument being proposed. Korean EFL learners with low NEST instruction may prefer to use stylistic conventions without as much creativity or awareness of the reader. Whereas Korean EFL learners with less NEST support may rely more heavily on speech formulas and collocational knowledge, Korean EFL learners with more NEST support may be more creative in composition, choosing to express personal opinions about the validity or invalidity of an argument. While more creative, these learners may also use more incorrect or awkward phrases.

\section{Research question four: differences in grammar}

As with aspects of content and style, grammar within writing of Korean EFL learner groups differed in several distinct ways. Aspects of verb tense and agreement appeared much more frequently in the Korean EFL learner groups with more NEST support. For the word $d o$, third person singular, past and present perfect tenses were used more often in the writing of Korean learners with extensive instruction from native speakers (See Table 5).

Conversely, frequency of the past tense in the word could was larger in the Korean group with low NEST support. Overall, this finding, along with larger values for root words like do and can among learners with little instruction from native English speakers, may reveal a tendency to rely on basic modals and formulaic expressions for hedging.

Concerning grammatical features associated with nouns, the high native support group of Korean EFL learners and native English speakers used I more often, supporting a claim that personal experience and opinion is used more extensively to support arguments of these groups. Such usage may represent an attempt to provide personal opinions that are designed to influence the reader. Korean EFL learners with low NEST support used we and you more often. This method to connect with the reader appears more neutral, perhaps supporting the contention that writings from Korean EFL learners with less NEST instruction are more impartial, logical, and formulaic.

Korean EFL learners with low NEST support used determiners less often than other groups (Table 5). Use of the indefinite article by Korean EFL learners with high NEST support more closely resembled that of native English speakers than their counterparts. However, the definite article, the, was used by Korean EFL learners with high NEST support much more often than native English speakers, perhaps reflecting a growing 
Table 5 Selected indicators for verb, noun, and clause use

\begin{tabular}{|c|c|c|c|c|}
\hline & & Low native support & High native support & Native \\
\hline \multirow[t]{6}{*}{ Auxiliary verbs } & Do & 42 & 33 & 58 \\
\hline & Does & 4 & 5 & 5 \\
\hline & Did & 1 & 3 & 4 \\
\hline & Done & 0 & 4 & 2 \\
\hline & Can & 148 & 93 & 62 \\
\hline & Could & 20 & 14 & 7 \\
\hline \multirow[t]{4}{*}{ Pronouns } & । & 103 & 130 & 211 \\
\hline & We & 65 & 38 & 32 \\
\hline & You & 30 & 12 & 62 \\
\hline & They & 158 & 114 & 97 \\
\hline \multirow[t]{3}{*}{ Determiners } & A & 207 & 214 & 289 \\
\hline & $A n$ & 13 & 20 & 20 \\
\hline & The & 320 & 383 & 332 \\
\hline \multirow[t]{7}{*}{ Clauses and coordinators } & If & 66 & 47 & 56 \\
\hline & And & 158 & 180 & 244 \\
\hline & Addition & 3 & 7 & 3 \\
\hline & Which & 29 & 21 & 20 \\
\hline & Who & 44 & 38 & 34 \\
\hline & How & 13 & 21 & 18 \\
\hline & Whether & 1 & 4 & 6 \\
\hline
\end{tabular}

awareness of the grammatical feature, albeit an incomplete one. Because this feature is imbued with information about general cultural use (e.g., the sun), immediate situational use (e.g., Don't go in there, the dog will bite you), local use (e.g., the car), and anaphoric use (e.g., I bought a cat. The cat's name is Whiskers), an increase of determiners may reflect growing awareness of contextual relationships between nouns and other elements of a sentence or composition. It may also reflect a heightened understanding of the reader's perspective (Celce-Murcia, Larsen-Freeman, \& Williams, 1999).

It appears that larger clauses or sentences were more frequent in the Korean EFL learners with high NEST support and native English speakers, who used words like and and addition more often. Korean EFL learners with low NEST support tended to add complexity and content to individual sentences using relative clauses. This group used relative pronouns like which and who more often than other groups. It also used if more extensively, along with modals like will, can, or should be able to (e.g., "if it is banned, it could make Cleaner Street"). Greater reliance on such logical phrases may support the assertion that content of Korean EFL learners with less NEST instruction is more formulaic, being focused on unbiased interpretation rather than personal evaluation or devices to influence the reader. More frequent use of the words how and whether by Korean EFL learners with high NEST support and native English writers may suggest a higher emphasis on process.

Grammatical differences between Korean EFL learner groups may be illustrated through two excerpts from the ICNALE corpus. The following comes from a Korean EFL learner with more extensive support from NESTs: 
I read an article, which is about whether teenagers should have a part time job. In today's society, more and more college students have part time job after school. In my opinion, I support that teenagers have part time jobs in their free time and the reasons are as follows. First, I think that having a part time job can train the teenagers how to earn money and let them know that it is not an easy thing to make money.

From the excerpt, we can see not only a large emphasis on the first person, but a clear attempt to express the opinion of the author. In addition, the word and is used to construct longer sentences. While there is a clear focus on meaning, grammatical accuracy is inconsistent. The determiner in "a part time job" is correctly used in one context, yet it is absent in another. Collocations like "I support that" also have contextual clarity but are grammatically incorrect. This style contrasts significantly with texts from learners with little or no native English instruction. Refer to the following excerpt from a Korean EFL learner with little or no support from NESTs:

Have you ever seen people who smoke in the restaurant? Most people in Korea do not like a person who smokes in the restaurants, so smoking has been banned in most of Korean restaurants. However, there are still some restaurants where people are allowed to smoke. In my opinion, smoking should be banned at all restaurants in this country. The reasons are below. First, other people in the restaurants can feel uncomfortable .....

As suggested in quantitative analysis, learners use more relative clauses to expand nouns (people who smoke, a person who smokes, restaurants where people are allowed to smoke). While the writer attempts to make an opinion, vague references to people, as well as phrases such as "most of Korean restaurants" and "some restaurants," appear to bleach out the perspective of the author, making it more difficult to discern the writer's opinion. Questions such as "Have you ever seen people who smoke in the restaurant?" use the word you to address the reader, yet they appear mechanical and are not designed to influence the reader's opinion. At the same time, there appears to be a heightened awareness of grammar, as is revealed by the use of the determiner the. This feature is consistently used throughout the text. Within "the restaurants," however, no specificity is needed. In this case, the object is not known by both the writer and the reader. Such an error reflects an awareness of grammatical accuracy, yet it does not reflect awareness of context or the reader.

\section{Conclusion}

Analysis of word usage has revealed key differences in the essays of Korean EFL writers who have had extensive NEST instruction and those who have not. Compositions by Korean EFL writers with more NEST instruction closely resemble native English writers in word frequency and usage. These essays also include more academic vocabulary, as well as a larger variety of word forms to enrich essay content. Concerning style, Korean EFL learners with more NEST instruction tend to use stances that evaluate, validate, and state personal opinions about an argument. Learners with low NEST instruction 
appear to rely on speech formulas, utilizing more unbiased logical arguments that do not reveal either the opinion of the author, nor an awareness of the reader.

Regarding grammar, Korean EFL learners with more NEST support show a heightened awareness of verb tense and agreement; use determiners more often than their counterparts with little NEST instruction; utilize the first person singular more often, which reveals a tendency to use personal experience to support an argument; and tend to combine phrases or sentences using the conjunctions and or addition. Learners with low NEST instruction use pronouns such as we, you, and they more often, which may be an attempt to avoid personal opinion. They also tend to utilize relative clauses to add complexity to sentences, rather than using conjunctions like and or addition. In general, use of grammar in the study suggests that while Korean EFL learners with extensive NEST instruction use more sophisticated vocabulary, word forms, and grammar to create a novel argument supported by personal experience, Korean EFL learners with low NEST instruction use formulaic and logical speech sequences to express opinions more accurately and neutrally.

Results of the study suggest that both EFL learner groups have distinct advantages. While learners with more NEST instruction made more creative and sophisticated constructions, their counterparts were more grammatically accurate in their use of language. Such results have implications for language teachers in EFL contexts such as South Korea, which have a variety of schools staffed with both NEST and NNEST instructors. Learners who are taught extensively by NEST instructors may benefit more from exercises that utilize formulaic language, as well as grammar instruction to assist with the editing process. Learners without instruction from NESTs may benefit from increased tasks that cultivate creativity with language and critical thinking. Specialized instruction in this way may allow all learners to add rhetorical and linguistic variety, while cultivating greater grammatical accuracy.

Although this study has provided useful information concerning EFL writing instruction, limitations in method still exist, highlighting a need for further research. The present study only used a self-survey to report time spent with NESTs, which limited understanding of each learner's educational background. Since educational policies that encourage the hiring of more NESTs may also be coupled with curricular changes, such as the addition of communicative tasks with more speaking and writing, any relationships between these potential covariates must be further investigated. More experimental or qualitative studies documenting curricular experiences of learners in conjunction with teacher influences can provide a holistic understanding of the EFL learner process, which may then be used to substantially improve instruction. Such study may help educators to develop policies and pedagogical techniques that combine the strengths of diverse groups, thereby enhancing the efficacy of English instruction.

Acknowledgements

Not Applicable.

Authors' contributions

All authors read and approved the final manuscript.

Funding

Not Applicable.

Availability of data and materials

All materials for this study are available through the ICNALE corpus. 


\section{Competing interests}

The authors declare that they have no competing interests.

Received: 12 October 2019 Accepted: 11 February 2020

Published online: 18 February 2020

\section{References}

Andrews, S., \& Svalberg, A. M. L. (2017). Teacher language awareness. In J. Cenoz, D. Gorter, \& S. May (Eds.), Language awareness and multilingualism. Encyclopedia of language and education (3rd ed., pp. 219-231). New York: Springer.

Brewer, A. (2016). A study of the different perceptions of the role and traits of Native English-Speaking Teachers (NESTS) in South Korea at the university level. St. Cloud: St. Cloud University Press Retrieved from http://repository.stcloudstate.edu/cgi/ viewcontent.cgi?article $=1046 \&$ context=engl_etds.

Browne, C., Culligan, B., \& Phillips, J. (2013). New General Service List: The most important words for second language learners of English. Retrieved from http://www.newgeneralservicelist.org

Byun, K., Chu, H., Kim, M., Park, I., Kim, S., \& Jung, J. (2011). English medium teaching in Korean higher education: Policy debates and reality. Higher Education, 62(4), 431-449 https://doi.org/10.1007/s10734-010-9397-4.

Celce-Murcia, M., Larsen-Freeman, D., \& Williams, H. A. (1999). The grammar book: An ESL/EFL teacher's course (2nd ed.). New York: Heinle \& Heinle Publishers.

Chun, S. Y. (2014). EFL learners' beliefs about native and non-native English-speaking teachers: Perceived strengths, weaknesses, and preferences. Journal of Multilingual and Multicultural Development, 35(6), 563-579 https://doi.org/10. 1080/01434632.2014.889141.

Copland, F., Davis, M., Garton, S., \& Mann, S. (2016). Investigating NEST schemes around the world: Supporting NEST/LET collaborative practices. London: British Council Retrieved from http://www.teachingenglish.org.uk/sites/teacheng/files/BC_ Report_online_screen_res_final_te.pdf.

Coxhead, A. (2000). A new academic word list. TESOL Quarterly, 34(2), 213-238 https://doi.org/10.2307/3587951.

DeKeyser, R. (2015). Skill acquisition theory. In B. VanPatten \& J. Williams (Eds.), Theories in second language acquisition: An introduction (pp. 94-112). New York: Routledge.

DeWaelsche, S. A. (2015). Critical thinking, questioning and student engagement in Korean university English courses. Linguistics and Education, 32, 131-147 https://doi.org/10.1016/j.linged.2015.10.003.

Discourse [Def. 3]. (2020). Merriam-Webster Online. In Merriam-Webster Retrieved from http://www.merriam-webster.com/ dictionary/citation.

Dyson, B. (2018). Developmental sequences. In J. I. Liontas (Ed.), The TESOL encyclopedia of English language teaching. Hoboken: Wiley.

Dyson, B. P., \& Håkansson, G. (2017). Understanding second language processing: A focus on processability theory (Vol. 4). Amsterdam: John Benjamins Publishing Company.

Harper, C., \& De Jong, E. (2004). Misconceptions about teaching English-language learners. Journal of Adolescent \& Adult Literacy, 48(2), 152-162 https://doi.org/10.1598/JAAL.48.2.6.

Ishikawa, S. (2013). The ICNALE and sophisticated contrastive interlanguage analysis of Asian learners of English. In S. Ishikawa (Ed.), Learner corpus studies in Asia and the world (pp. 91-118). Kobe: Kobe University Press Retrieved from http://www.lib. kobe-u.ac.jp/infolib/meta_pub/G0000003kernel_81006678.

Ishikawa, S. (2018). ICNALE: The international Corpus network of Asian learners of English. Kobe: Kobe University Press Retrieved from http://language.sakura.ne.jp/icnale/.

Jiang, W., \& Li, W. (2018). Linking up learners of Chinese with native speakers through WeChat in an Australian tertiary CFL curriculum. Asian-Pacific Journal of Second and Foreign Language Education, 3(1), 14 https://doi.org/10.1186/s40862-0180056-0.

Jung, M. H. (2019). Korea lifts English education ban for first, second graders. The Korea times Retrieved from https://www. koreatimes.co.kr/www/nation/2019/03/181_265365.html.

Kang, S. W. (2009). Koreans ranked bottom in English proficiency test. In The Korea times Retrieved from http://www. koreatimes.co.kr/www/news/nation/2009/04/117_42399.html.

Keh, C. (2017). But... what will the students think? Factors shaping university English language teachers' decisions to teach grammar. The Journal of Asia TEFL, 14(3), 501-514 https://doi.org/10.18823/asiatefl.2017.14.3.8.501.

Kim, E. G. (2014). Korean engineering professors' views on English language education in relation to English-medium instruction. The Journal of Asia TEFL, 11(2), 1-33 Retrieved from http://journal.asiatefl.org/.

Kim, J., \& Kim, J. (2005). Teaching Korean university writing class. Asian EFL Journal, 7(2), 69-90 Retrieved from https://asian-efljournal.com/June_05_yk\&jk.pdf.

Kim, S., \& Lee, J. H. (2010). Private tutoring and demand for education in South Korea. Economic Development and Cultural Change, 58(2), 259-296 https://doi.org/10.1086/648186

Kwon, O., Yoshida, K., Watanabe, Y., Negishi, M., \& Naganuma, N. (2004). A comparison of English proficiency of Korean, Japanese and Chinese high school students. English Education, 59(4), 3-21 Retrieved from http://kate.bada.cc/wpcontent/uploads/2015/02/kate_59_4_1.pdf.

Laufer, B., \& Nation, P. (1995). Vocabulary size and use: Lexical richness in L2 written production. Applied Linguistics, 16(3), 307-322 https://doi.org/10.1093/applin/16.3.307.

Lu, X. (2012). The relationship of lexical richness to the quality of ESL learners' oral narratives. The Modern Language Journal, 96(2), 190-208 https://doi.org/10.1111/j.1540-4781.2011.01232_1.x.

Ma, L. (2012). Advantages and disadvantages of native- and nonnative-English-speaking teachers: Student perceptions in Hong Kong. TESOL Quarterly, 46(2), 280-305 https://doi.org/10.1002/tesq.21.

Master, P. (1996). Systems in English grammar: An introduction for language teachers. Upper Saddle River: Prentice Hall Regents.

Min, S., Paek, J. K., \& Kang, Y. (2019). Exploring the use of hedges and stance devices in relation to Korean EFL learners' argumentative writing qualities. English Teaching, 74(1), 3-23 https://doi.org/10.15858/engtea.74.1.201903.3.

Moodie, I., \& Nam, H. J. (2016). English language teaching research in South Korea: A review of recent studies (2009-2014). Language Teaching, 49(1), 63-98 https://doi.org/10.1017/S026144481500035X. 
Murphy, M. L. (2010). Lexical meaning. New York: Cambridge University Press.

Niederhauser, J. S. (2012). Motivating learners at south Korean universities. English Teaching Forum, 50(3), 28-31 Retrieved from https://eric.ed.gov/?id=EJ997526.

Ortaçtepe, D. (2013). Formulaic language and conceptual socialization: The route to becoming nativelike in L2. System, 41(3), 852-865 https://doi.org/10.1016/j.system.2013.08.006

Pérez-Llantada, C. (2014). Formulaic language in L1 and L2 expert academic writing: Convergent and divergent usage. Journal of English for Academic Purposes, 14, 84-94 https://doi.org/10.1016/j.jeap.2014.01.002.

Pienemann. (1989). Is language teachable? Psycholinguistic experiments and hypotheses. Applied Linguistics, 10(1), 52-79 https://doi.org/10.1093/applin/10.1.52.

Programme for International Student Assessment (PISA). (2015). PISA 2015 key findings for Korea. Retrieved from https:// www.oecd.org/korea/pisa-2015-korea.htm

Read, J. (2000). Assessing vocabulary. Cambridge: Cambridge University Press.

Stoeckel, T., \& Bennett, P. (2015). A test of the new general service list. Vocabulary Learning and Instruction, 4(1), 1-8 Retrieved from http://vli-journal.org.

Ulla, M. B. (2019). Filipinos as EFL teachers in Bangkok, Thailand: Implications for language education policy in the ASEAN region. RELC Journal (OnlineFirst), 1-15 https://doi.org/10.1177/0033688219879775.

Veliz, L. (2017). Enhancing ESL learners' vocabulary learning of metaphorically-used words. Journal of Language Teaching and Research, 8(5), 835-846 https://doi.org/10.17507/jltr.0805.01.

Wang, L. Y., \& Lin, T. B. (2013). The representation of professionalism in native English-speaking teacher's recruitment policies: A comparative study of Hong Kong, Japan, Korea and Taiwan. English Teaching, 12(3), 5-22 Retrieved from https:// edlinked.soe.waikato.ac.nz/research/files/etpc/files/2013v12n3art1.pdf.

White, L. (2009). Second language acquisition and universal grammar. New York: Cambridge University Press.

Yu, G. (2009). Lexical diversity in writing and speaking task performances. Applied Linguistics, 31(2), 236-259 https://doi.org/10. 1093/applin/amp024.

\section{Publisher's Note}

Springer Nature remains neutral with regard to jurisdictional claims in published maps and institutional affiliations.

\section{Submit your manuscript to a SpringerOpen ${ }^{\circ}$ journal and benefit from:}

- Convenient online submission

- Rigorous peer review

- Open access: articles freely available online

High visibility within the field

- Retaining the copyright to your article

Submit your next manuscript at $>$ springeropen.com 